\title{
Evolution of a family of metazoan active-site-serine enzymes from penicillin-binding proteins: a novel facet of the bacterial legacy Nina Peitsaro ${ }^{1,2}$, Zydrune Polianskyte ${ }^{1,2}$, Jarno Tuimala3 ${ }^{3}$ Isabella Pörn- Ares $^{1,2}$, Julius Liobikas², Oliver Speer ${ }^{2}$, Dan Lindholm ${ }^{4}$, James Thompson ${ }^{5}$ and Ove Eriksson*1,2
}

\begin{abstract}
Address: ${ }^{1}$ Research Program of Molecular Neurology, Biomedicum Helsinki, P.O. Box 63, FIN-00014 University of Helsinki, Finland, ${ }^{2} \mathrm{Helsinki}$ Biophysics and Biomembrane Group, Institute of Biomedicine, P.O. Box 63, FIN-00014 University of Helsinki, Finland, ${ }^{3}$ CSC-Scientific Computing Ltd, P.O. Box 405, FIN-02101 Espoo, Finland, ${ }^{4}$ Minerva Medical Research Institute, Biomedicum Helsinki, FIN-00290 Helsinki, Finland and ${ }^{5}$ Androgen Receptor Laboratory, Institute of Biomedicine, P.O. Box 63, FIN-00014 University of Helsinki, Finland

Email: Nina Peitsaro - Nina.Peitsaro@helsinki.fi; Zydrune Polianskyte - Zydrune.Polianskyte@helsinki.fi; Jarno Tuimala - jtuimala@csc.fi; Isabella Pörn-Ares - Isabella.Ares@helsinki.fi; Julius Liobikas - julius.liobikas@mail.lt; Oliver Speer - oliver.speer@kispi.unizh.ch; Dan Lindholm - dan.lindholm@helsinki.fi; James Thompson - James.Thompson@ helsinki.fi; Ove Eriksson* - ove.eriksson@helsinki.fi

* Corresponding author
\end{abstract}

Published: 28 January 2008

BMC Evolutionary Biology 2008, 8:26 doi:10.1186/147/-2148-8-26
Received: I May 2007

Accepted: 28 January 2008

This article is available from: http://www.biomedcentral.com/I47I-2I48/8/26

(c) 2008 Peitsaro et al; licensee BioMed Central Ltd.

This is an Open Access article distributed under the terms of the Creative Commons Attribution License (http://creativecommons.org/licenses/by/2.0), which permits unrestricted use, distribution, and reproduction in any medium, provided the original work is properly cited.

\begin{abstract}
Background: Bacterial penicillin-binding proteins and $\beta$-lactamases (PBP- $\beta$ Ls) constitute a large family of serine proteases that perform essential functions in the synthesis and maintenance of peptidoglycan. Intriguingly, genes encoding PBP- $\beta$ L homologs occur in many metazoan genomes including humans. The emerging role of LACTB, a mammalian mitochondrial PBP- $\beta$ L homolog, in metabolic signaling prompted us to investigate the evolutionary history of metazoan PBP- $\beta \mathrm{L}$ proteins.

Results: Metazoan PBP- $\beta$ L homologs including LACTB share unique structural features with bacterial class $B$ low molecular weight penicillin-binding proteins. The amino acid residues necessary for enzymatic activity in bacterial PBP- $\beta L$ proteins, including the catalytic serine residue, are conserved in all metazoan homologs. Phylogenetic analysis indicated that metazoan PBP- $\beta \mathrm{L}$ homologs comprise four alloparalogus protein lineages that derive from $\alpha$-proteobacteria.

Conclusion: While most components of the peptidoglycan synthesis machinery were dumped by early eukaryotes, a few PBP- $\beta$ L proteins were conserved and are found in metazoans including humans. Metazoan PBP- $\beta \mathrm{L}$ homologs are active-site-serine enzymes that probably have distinct functions in the metabolic circuitry. We hypothesize that PBP- $\beta$ L proteins in the early eukaryotic cell enabled the degradation of peptidoglycan from ingested bacteria, thereby maximizing the yield of nutrients and streamlining the cell for effective phagocytotic feeding.
\end{abstract}

\section{Background}

Penicillin-binding proteins and $\beta$-lactamases (PBP- $\beta$ Ls) are serine proteases that are distinguished by a catalytic -
SXXK-motif (X is any amino acid) [1-5]. Due to their vital role in bacterial biology, PBP- $\beta$ Ls are of importance both medically and economically. Penicillin-binding proteins 
synthesize and maintain peptidoglycan, the major cell wall component in most bacteria. Penicillin-binding proteins are inhibited by $\beta$-lactam antibiotics such as penicillins and cephalosporins which prevent peptidoglycan synthesis and therefore bacterial proliferation. As a defense mechanism against $\beta$-lactam antibiotics, some bacteria produce $\beta$-lactamases which hydrolyze the antibiotics into biologically inactive metabolites. Phylogenetic analyses show that $\beta$-lactamases have evolved from penicillin-binding proteins on at least three occasions indicating a recurrent need to protect/maintain the peptidoglycan synthesis machinery [3,6-8]. Many metazoan organisms including humans harbor proteins that share sequence similarity to PBP- $\beta$ Ls [9]. The genes for metazoan PBP- $\beta \mathrm{L}$ homologs most likely derive from bacteria and may have been acquired by either horizontal or endosymbiotic gene transfer. However, the almost universal lack of peptidoglycan synthesis in eukaryotes raises the questions of (i) what immediate benefit(s) PBP- $\beta \mathrm{L}$ proteins conferred to the recipient cell, and (ii) what biochemical properties the PBP- $\beta \mathrm{L}$ proteins were later endowed with, that lead to their integration in the protein repertoire of higher metazoan species.

Based on amino acid sequence, 3-dimensional structure, and domain organization, bacterial PBP- $\beta$ Ls can be categorized into low molecular weight penicillin-binding proteins classes $\mathrm{A}$ to $\mathrm{C}$, high molecular weight penicillinbinding proteins classes $\mathrm{A}$ to $\mathrm{C}$, and $\beta$-lactamases classes $\mathrm{A}, \mathrm{C}$, and D [2-5]. The structure and catalytic mechanism of PBP- $\beta$ Ls have been extensively studied $[1-6,10]$. All PBP- $\beta$ Ls share three conserved active site motifs which contribute to the formation of the catalytic cavity [1-5]. The -SXXK-motif contains the catalytic serine residue which undergoes acylation and deacylation cycles. The [SY]X[NT]-motif harbors side chains that point into the active site cleft and participate in the catalytic process. The -[KH][ST]G-motif is located in a $\beta$-sheet and participates in substrate docking through antiparallel backbone hydrogen bonding. The arrangement of the three active site motifs along the amino acid sequence is distinctive for each PBP- $\beta$ L class $[2-5]$. The size of the PBP- $\beta \mathrm{L}$ domain varies from about 200 amino acids in class $D \beta$-lactamases to over 400 amino acids in class $C$ low molecular weight penicillin-binding proteins, indicating that the PBP- $\beta \mathrm{L}$ domain has undergone extensive diversification through modification of local structural elements [1-5].

LACTB is a mammalian protein comprised of a mitochondrial import sequence and a domain sharing sequence similarity to PBP- $\beta$ Ls (human LACTB, [SwissProt:P83111]). This domain is 450 amino acids long and the three PBP- $\beta$ L active site motifs (-SISK-, -YST-, and HTG-) have been identified through sequence comparisons with bacterial PBP- $\beta$ Ls $[9,11]$. LACTB has been detected in several mitochondrial proteome survey studies suggesting that LACTB is a ubiquitous protein in mammalian mitochondria [12-15]. LACTB is subjected to regulation at transcriptional and posttranslational level. In skeletal muscle, LACTB expression is rapidly increased by insulin [16] implying a role in anabolic processes. In liver, lysine acetylation of LACTB occurs during starvation [17] suggesting that LACTB, like several key enzyme in metabolism, is regulated by the highly conserved acetyltransferase/deacetylase pathway [18]. The catalytic serine residue located in the -SISK-motif is phosphorylated under normal conditions suggesting that LACTB is activated by a specific phosphoprotein phosphatase [19]. However, the enzymatic substrates and physiological function of LACTB remains unknown.

Here we have investigated the evolutionary history of LACTB and other metazoan PBP- $\beta$ Ls homologs, which we herein refer to as the LACTB family. A combined phylogenetic and structural analysis demonstrated that the LACTB family has evolved from class B low molecular weight penicillin-binding proteins (LPBP-B). The presence of the conserved catalytic serine residue in all LACTB family proteins suggest that they have peptidase or esterase activity.

\section{Results and discussion LACTB shares conserved active site signature motifs with bacterial PBP- $\beta$ L proteins}

We performed extensive database searches for proteins sharing sequence similarity with human LACTB. Metazoan proteins containing the three active site motifs SXXK-, -[SY]X[NT]-, and -[KH][ST]G-shared by all PBP$\beta$ Ls [1-6], were classified as LACTB family proteins (Table 1). LACTB orthologs were identified using the reciprocal best-hit approach $[20,21]$. We found that all completed vertebrate genomes harbor a LACTB ortholog. We also identified LACTB orthologs in Ciona intestinalis, Strogylocentrotus purpuratus, Caenorhabditis elegans, Caenorhabditis briggsae, Schistosoma japonicum, and Dictyostelium discoideum. An amino acid alignment of the active site motifs and their flanking regions is shown (Figure 1, panel A). For comparison we included the corresponding amino acid segments from the D-alanyl-D-alanine carboxypeptidase [Swiss-Prot:P15555] of the actinobacterium Streptomyces sp. strain R61, which is perhaps the most extensively studied PBP- $\beta$ L family protein $[22,23]$. The alignment shows that the active site motifs and the catalytic serine residue are conserved in all taxa from bacteria to human suggesting that LACTB is an active-site-serine enzyme. In addition, several amino acids flanking the active site motifs are conserved from bacteria to human further suggesting that LACTB and the bacterial PBP- $\beta$ L proteins share common features in the secondary and tertiary structure. Metazoan LACTB orthologs harbor a 50-100 amino acid long $\mathrm{N}$-terminal region with no sequence sim- 
Table I: Accession Numbers and Proposed Classification of Proteins Used in This Study

\begin{tabular}{|c|c|c|c|c|}
\hline Species & Accession number & Database & Proposed classification & Reference \\
\hline \multicolumn{5}{|l|}{ EUKARYOTA } \\
\hline \multicolumn{5}{|l|}{ Vertebrata } \\
\hline Bos taurus & P83095 & Swiss-Prot & LACTB & {$[12]$} \\
\hline Bos taurus & XP_601949 & RefSeq & LACTB-like protein 2 & \\
\hline Canis familiaris & $X P \_5447 \mid 3$ & RefSeq & LACTB & [47] \\
\hline Danio rerio & NP_001018429 & RefSeq & LACTB & \\
\hline Fugu rubipes & SINFRUP00000138119 & Ensembl & LACTB & \\
\hline Gallus gallus & Q5ZKI2 & Swiss-Prot & LACTB & {$[48]$} \\
\hline Gallus gallus & XP_00I232283 & RefSeq & LACTB-like protein 2 & {$[48]$} \\
\hline Gasterosteus aculeatus & ENSGACP000000I4046 & Ensembl & LACTB & \\
\hline Homo sapiens & P83111 & Swiss-Prot & LACTB & [9] \\
\hline Homo sapiens & $\overline{\text { XP_934300 }}$ & RefSeq & LACTB-like protein 2 & \\
\hline Macaca mulatta & ENSMMUP000000047I9 & Ensembl & LACTB & \\
\hline Monodephis domestica & ENSMODP000000I3893 & Ensembl & LACTB & \\
\hline Mus musculus & Q9EP89 & Swiss-Prot & LACTB & {$[11,13]$} \\
\hline Mus musculus & XP_205950 & RefSeq & LACTB-like protein 2 & \\
\hline Oryctolagus cuniculus & ENSOCUP00000008608 & Ensembl & LACTB & \\
\hline Oryzias latipes & ENSORLP00000009787 & Ensembl & LACTB & \\
\hline Tetrodon nigroviridis & CAG03509 & GenPept & LACTB-like protein 2 & [49] \\
\hline Tetrodon nigroviridis & GSTENP000I594900I & Ensembl & LACTB & [49] \\
\hline Xenopus tropicalis & ENSXETG00000009720 & Ensembl & LACTB & \\
\hline \multicolumn{5}{|l|}{ Tunicata } \\
\hline Ciona intestinalis & ENSCING00000006798 & Ensembl & LACTB & {$[50]$} \\
\hline \multicolumn{5}{|l|}{ Echinodermata } \\
\hline Strongylocent. purpuratus & XP_781179 & RefSeq & Esterase-like & \\
\hline Strongylocent. purpuratus & XP_78|24I & RefSeq & Esterase-like & \\
\hline Strongylocent. purpuratus & XP_789736 & RefSeq & LACTB & \\
\hline \multicolumn{5}{|l|}{ Nematoda } \\
\hline Caenorhabditis briggsae & CAE57335 & GenPept & LACTB-like protein I & [5। $]$ \\
\hline Caenorhabditis briggsae & CAE57450 & GenPept & Esterase-like & {$[51]$} \\
\hline Caenorhabditis briggsae & CAE59629 & GenPept & Esterase-like & {$[51]$} \\
\hline Caenorhabditis briggsae & CAE67822 & GenPept & Esterase-like & {$[51]$} \\
\hline Caenorhabditis briggsae & CAE7320I & GenPept & Esterase-like & {$[51]$} \\
\hline Caenorhabditis briggsae & CAE74593 & GenPept & LACTB & {$[51]$} \\
\hline Caenorhabditis briggsae & CAE75I5I & GenPept & LACTB-like protein I & {$[51]$} \\
\hline Caenorhabditis elegans & NP_001041033 & RefSeq & LACTB & {$[52]$} \\
\hline Caenorhabditis elegans & NP_495790 & RefSeq & Esterase-like & [52] \\
\hline Caenorhabditis elegans & $N P \_496176$ & RefSeq & Esterase-like & {$[52]$} \\
\hline Caenorhabditis elegans & NP_496299 & RefSeq & Esterase-like & {$[52]$} \\
\hline Caenorhabditis elegans & NP_50582I & RefSeq & LACTB-like protein I & {$[52]$} \\
\hline Caenorhabditis elegans & NP_50922I & RefSeq & Esterase-like & {$[52]$} \\
\hline Caenorhabditis elegans & NP_509969 & RefSeq & LACTB-like protein I & [52] \\
\hline \multicolumn{5}{|l|}{ Platyhelminthes } \\
\hline Schistosoma japonicum & $A A \times 27853, A A \times 25200$ & GenPept & LACTB & \\
\hline \multicolumn{5}{|l|}{ Mycetozoa } \\
\hline Dictyostelium discoideum & Q55CN2 & Swiss-Prot & LACTB & [53] \\
\hline Dictyostelium discoideum & $X P \_640123$ & RefSeq & LACTB-like protein 2 & [53] \\
\hline Dictyostelium discoideum & $X P \_640124$ & RefSeq & LACTB-like protein 2 & [53] \\
\hline Dictyostelium discoideum & $X P \_641364$ & RefSeq & LACTB-like protein 2 & {$[53]$} \\
\hline \multicolumn{5}{|l|}{ BACTERIA } \\
\hline Bradyrhizobium japonicum & NP_770552 & RefSeq & LPBP-Ba & \\
\hline Hyphomonas neptunium & YP_759849 & RefSeq & LPBP-Ba & \\
\hline Maricaulis maris & YP_755834 & RefSeq & LPBP-Ba & \\
\hline Mesorhizobium loti & $N P_{-}=107127$ & RefSeq & LPBP-Ba & \\
\hline Oceanicaulis alexandrii & YP_755834 & RefSeq & LPBP-Ba & \\
\hline Sphingopyxis alaskensis & YP_618034 & RefSeq & LPBP-Ba & \\
\hline \multicolumn{5}{|l|}{$\beta$-proteobacteria } \\
\hline Burkholderia gladioli & Q9KX40 & Swiss-Prot & LPBP-Ba & \\
\hline \multicolumn{5}{|l|}{ Bacillae } \\
\hline Bacillus cereus & ZP_00239307 & RefSeq & LPBP-Ba & \\
\hline \multicolumn{5}{|l|}{ Actinobacteria } \\
\hline Streptomyces sp. strain R6I & $\underline{P I 5555}$ & Swiss-Prot & & {$[22,23]$} \\
\hline Salinispora tropica & $\overline{Z P \_01429613}$ & RefSeq & LPBP-Ba & \\
\hline
\end{tabular}

NOTE.- aClassified according to the scheme of Massova and Mobashery [3]. 
ilarity to the Streptomyces D-alanyl-D-alanine carboxypeptidase or to any other bacterial PBP- $\beta \mathrm{L}$ protein. The $\mathrm{N}$-terminal region starts with a predicted mitochondrial import sequence (Figure 1, panel A). Comparison of the gene architecture of the metazoan LACTB orthologs (Figure 1, panel $B$ ) revealed extensive similarities of the exonintron organization supporting that these genes were vertically inherited from a common ancestor [24].

\section{Amino acid sequence and structural features indicate that LACTB derives from class $B$ low molecular weight penicillin-binding proteins}

Phylogenetic and structural analyses show that the bacterial PBP- $\beta$ L family is monophyletic and has diversified by local structural changes and domain fusions [1-8]. The bacterial PBP- $\beta \mathrm{L}$ family can be divided into seven distinct and highly divergent classes that share little or no interclass sequence identity except for the three common catalytic site motifs [2-8]. Proteins from the different PBP- $\beta \mathrm{L}$ classes are distinguished by the specific amino acids in the active site motifs and the number of amino acid residues between the three motifs [2-8]. The arrangement of the active site motifs along the amino acid sequence for a set of founding members of each bacterial PBP- $\beta$ L class is shown (Figure 2, Additional file 1). Comparing the arrangement of the active site motifs and their specific amino acids in human and C. elegans LACTB with the founding members of each of the bacterial PBP- $\beta \mathrm{L}$ classes revealed that LACTB is related to the LPBP-B proteins. Sequence comparison of the PBP- $\beta$ L domain of LACTB with the LPBP-B proteins indicated a moderate degree of sequence identity (16-27\%). Conversely, there was little or no inter-motif similarity between LACTB and the proteins belonging to the other bacterial PBP- $\beta \mathrm{L}$ classes. Based on comparison with the founding members of the PBP- $\beta$ L classes, LACTB can thus be classified as a LPBP-B protein. To test the global validity of this classification we investigated if all bacterial PBP- $\beta \mathrm{L}$ proteins sharing sequence similarity to LACTB are LBPB-B proteins. Searches in the NCBI nr database using human LACTB as the seed sequence yielded more than five hundred bacterial proteins. We divided these proteins into five categories based on E-value $\left(10^{-5}-10^{-10}, 10^{-10}-10^{-20}, 10^{-20}-10^{-30}\right.$, $10^{-30}-10^{-40}, 10^{-40}$ and lower). Ten proteins randomly chosen from each category were aligned with the founding members of the LBPB-B group. All the sampled bacterial proteins, irrespective of E-value, had a characteristic LPBPB type motif organization, shared 25-95\% sequence identity with the founding members of the LPBP-B class and had little or no sequence similarity with other PBP- $\beta \mathrm{L}$ classes. This result suggests that LACTB together with the LPBP-B proteins form a distinct class sharing a common ancestry.
At present, 3-dimensional structures are available for three LPBP-B class proteins: the Streptomyces D-alanyl-D-alanine carboxypeptidase $[22,23]$; a D-alanyl-D-alanine aminopeptidase from Ochrobactrum anthropii [SwissProt:Q9ZBA9] [25]; and a transesterase from Burkholderia gladioli [Swiss-Prot:Q9KX40] [26]. These three proteins representing different LPBP-B subclasses share an almost identical polypeptide fold consisting of an $\alpha / \beta$ region and an all-helical region, with the catalytic site located between them. Comparison of the amino acid sequences with the 3-dimensional structures of these LPBP-B proteins revealed several conserved amino acids in structurally critical elements of the polypeptide fold (Additional file 2). Amino acid alignments of LACTB with these LPBP$B$ proteins showed a high degree of amino acid conservation especially of amino acids in positions corresponding to these structural elements (Additional file 2). Evidently, local structure imposes particularly stringent constraints on substitutions in these positions promoting their conservation through long evolutionary distances. These findings strongly suggest that LACTB and the LPBP-B proteins share a similar polypeptide fold.

\section{The LACTB family comprises four paralogus lineages}

Having identified a set of LACTB orthologs we sought to determine the evolutionary relationship with other LACTB family proteins (Table 1). Amino acid sequence comparisons revealed that all LACTB family proteins have a LPBP-B-like motif arrangement and, moreover, share a $17-40 \%$ inter-motif sequence identity to human LACTB (Additional file 3). This finding suggests that the LACTB family descended from a common bacterial ancestor protein and then diversified in various metazoan lineages. The most extensive diversification of the LACTB family occurred in nematodes which have eight paralogs, whilst vertebrates harbor two paralogs. In contrast, all insects sequenced to date appear to lack LACTB proteins. To gain further insight into the evolutionary events shaping the LACTB family we performed a phylogenetic analysis.

The PBP- $\beta$ L domain of thirty-seven metazoan LACTB family proteins, four Dictyostelium LACTB homologs, and ten bacterial LPBP-B proteins were aligned and analyzed by maximum likelihood as described in Methods. The Streptomyces D-alanyl-D-alanine carboxypeptidase and two related LPBP-B proteins from Salinispora tropica and Bacillus cereus $\left(\mathrm{E}<10^{-50}\right.$ against Streptomyces $)$ were included as an outgroup (Table 1). The inferred best tree, shown in Figure 3, indicated that the LACTB family is composed of four groups. We have labeled the groups: (i) LACTB orthologs; (ii) LACTB-like 1; (iii) LACTB-like 2; and (iv) esterase-like proteins (Figure 3 ). These groups were supported by a bootstrap analysis of one hundred replicates. That the bacterial LPBP-B proteins were intercalated with the different LACTB groups, instead of forming a sister 


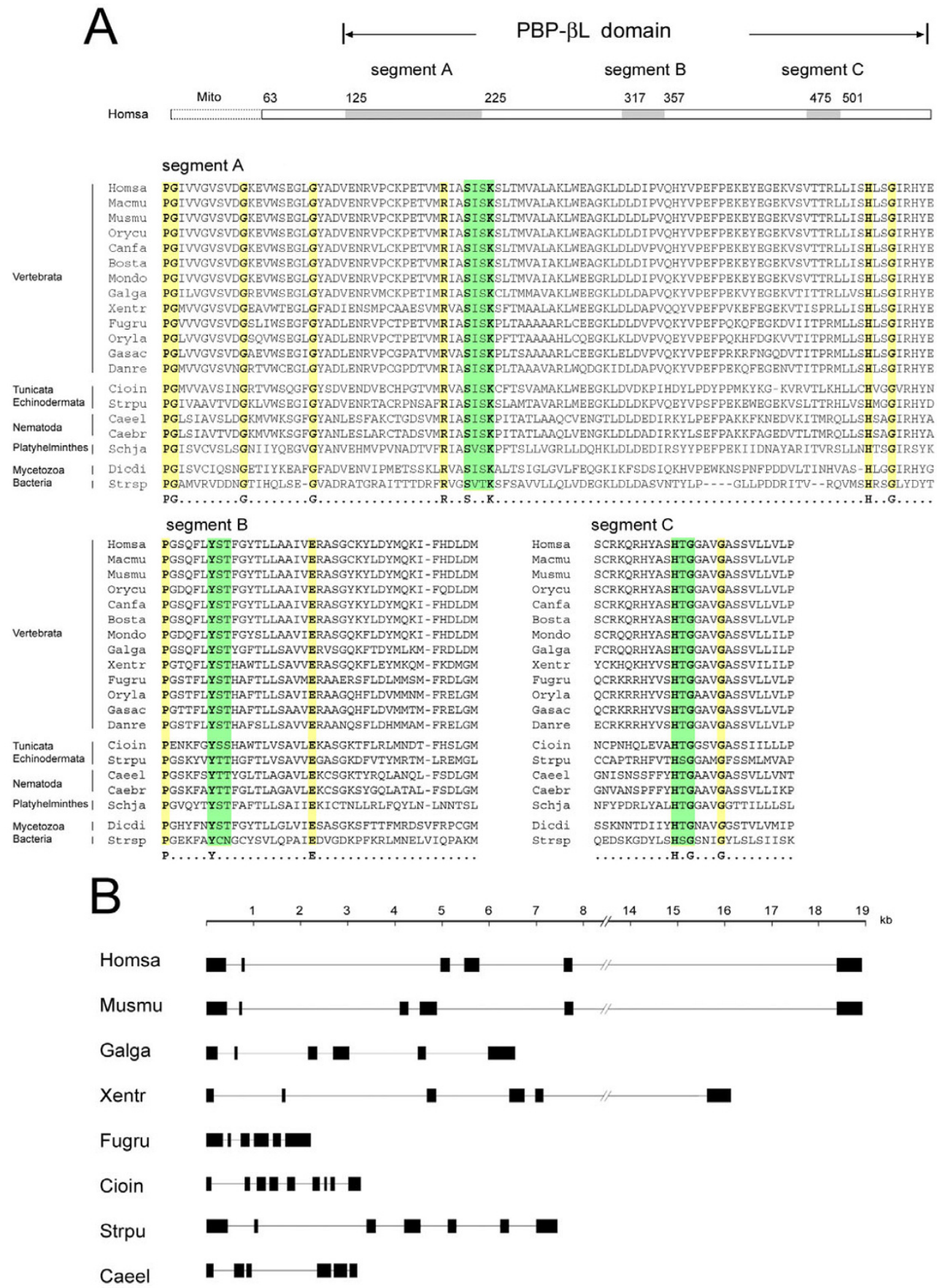

\section{Figure I}

Amino acid alignment of catalytic site motifs and gene architecture of LACTB orthologs. (A) Schematic organization and alignment of the three PBP- $\beta$ Ls catalytic site motifs (highlighted in green) and their flanking regions in LACTB orthologs. The corresponding motifs in the Streptomyces sp. strain R6I D-alanyl-D-alanine carboxypeptidase [Swiss-Prot:PI5555] are included. Abbreviations for species names, in order: Homsa, Homo sapiens (Swiss-Prot:P83III); Macmu, Macaca mulatta (Ensembl:ENSMMUP00000004719); Musmu, Mus musculus (Swiss-Prot:Q9EP89); Orycu, Oryctolagus cuniculus

(Ensembl:ENSOCUP00000008608); Canfa, Canis familiaris (RefSeq:XP_544713); Bosta, Bos taurus (Swiss-Prot:P83095); Mondo, Monodelphis domestica (Ensembl:ENSMODP000000 13893); Galga,Gallus gallus (Swiss-Prot:Q5ZK 12); Xentr, Xenopus tropicalis (Ensembl:ENSXETG00000009720); Fugru, Fugu rubipes (Ensembl:SINFRUP00000 I38I I9); Oryla, Oryzia latipes (Ensembl:ENSORLP00000009787); Gasac, Gasterosteus aculeatus

(Ensembl:ENSGACP000000 I 4046); Danre, Danio rerio (RefSeq:NP_001018429); Strpu, Strongylocentrotus purpuratus (RefSeq:XP 789736); Cioin, Ciona intestinalis (Ensembl:ENSCING00000006798); Schja, Schistosoma japonicum (GenPept:AAX27853, AAX25200); Caeel, Caenorhabditis elegans (RefSeq:NP_001041033); Caebr, Caenorhabiditis briggsae (GenPept:CAE74593); Dicdi, Dictyostelium discoideum (Swiss-Prot:Q55CN2); Stesp, Streptomyces sp strain R6I. The mitochondrial import sequence (Mito) is indicated. Amino acid conserved in all taxa are highlighted in yellow. (B) Organization of exons and introns in LACTB genes of representative metazoan taxa. 


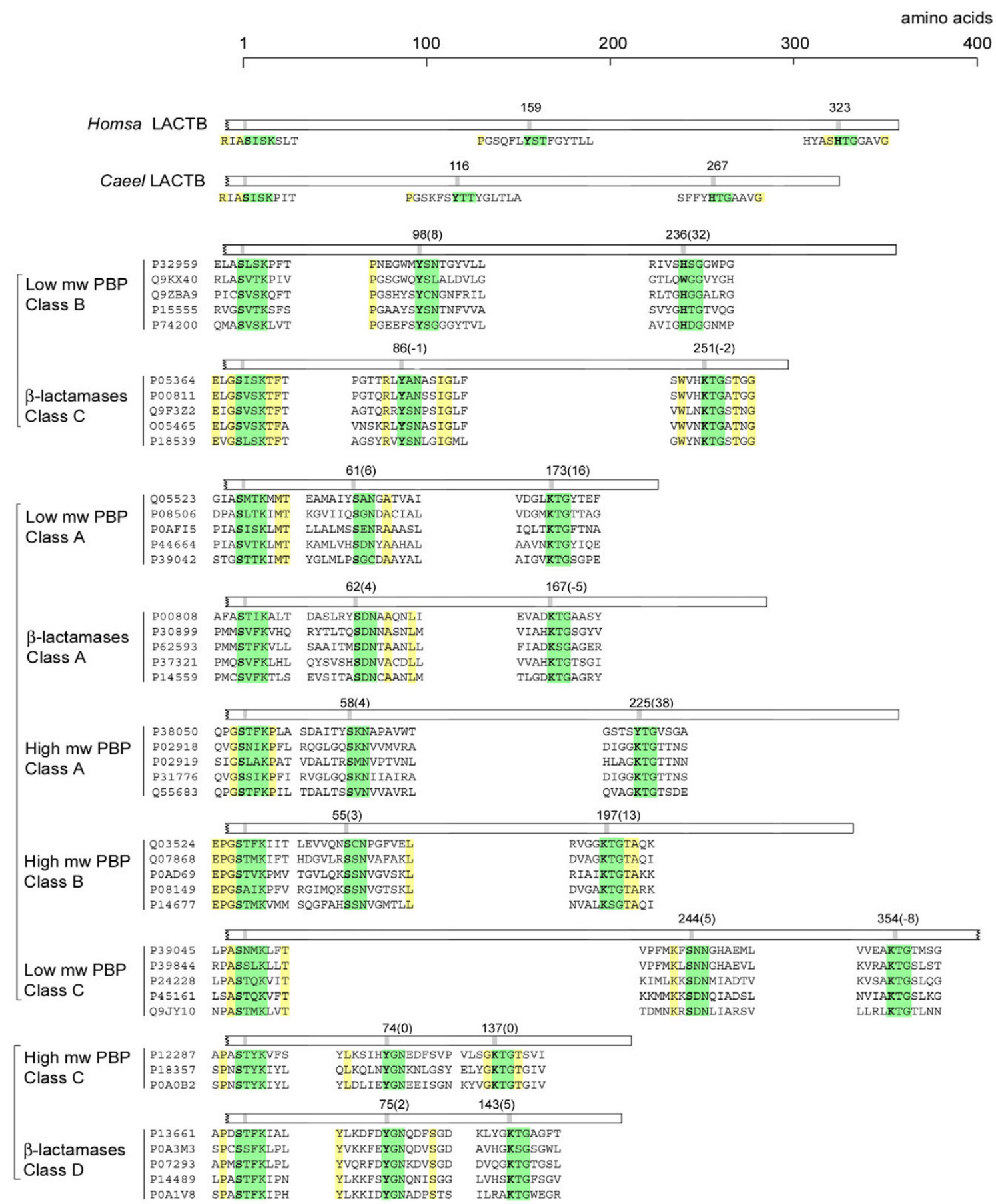

\section{Figure 2}

Schematic representation of the organization of the three catalytic site motifs in LACTB and the different PBP- $\beta$ L classes. A set of founding members of each PBP- $\beta$ L class (Additional file I), classified according to Ghuysen 1997, and Massova and Mobashery 1998 [3,4], were used to calculate the median inter-motif distances in number of amino acid residues. Accession numbers refer to the Swiss-Prot database. The catalytic site motifs are highlighted in green and invariant amino acids are higlighted in yellow. Inter-motif distances were measured from the serine in the -SXXK-motif to the serine/lysine and lysine/histidine of the second and third catalytic site motif, respectively. Numbers within brackets is the largest difference from the median value within each class. PBP- $\beta$ L classes forming separate clades [3] are marked with square brackets. Abbreviations: PBP, penicillinbinding protein. 


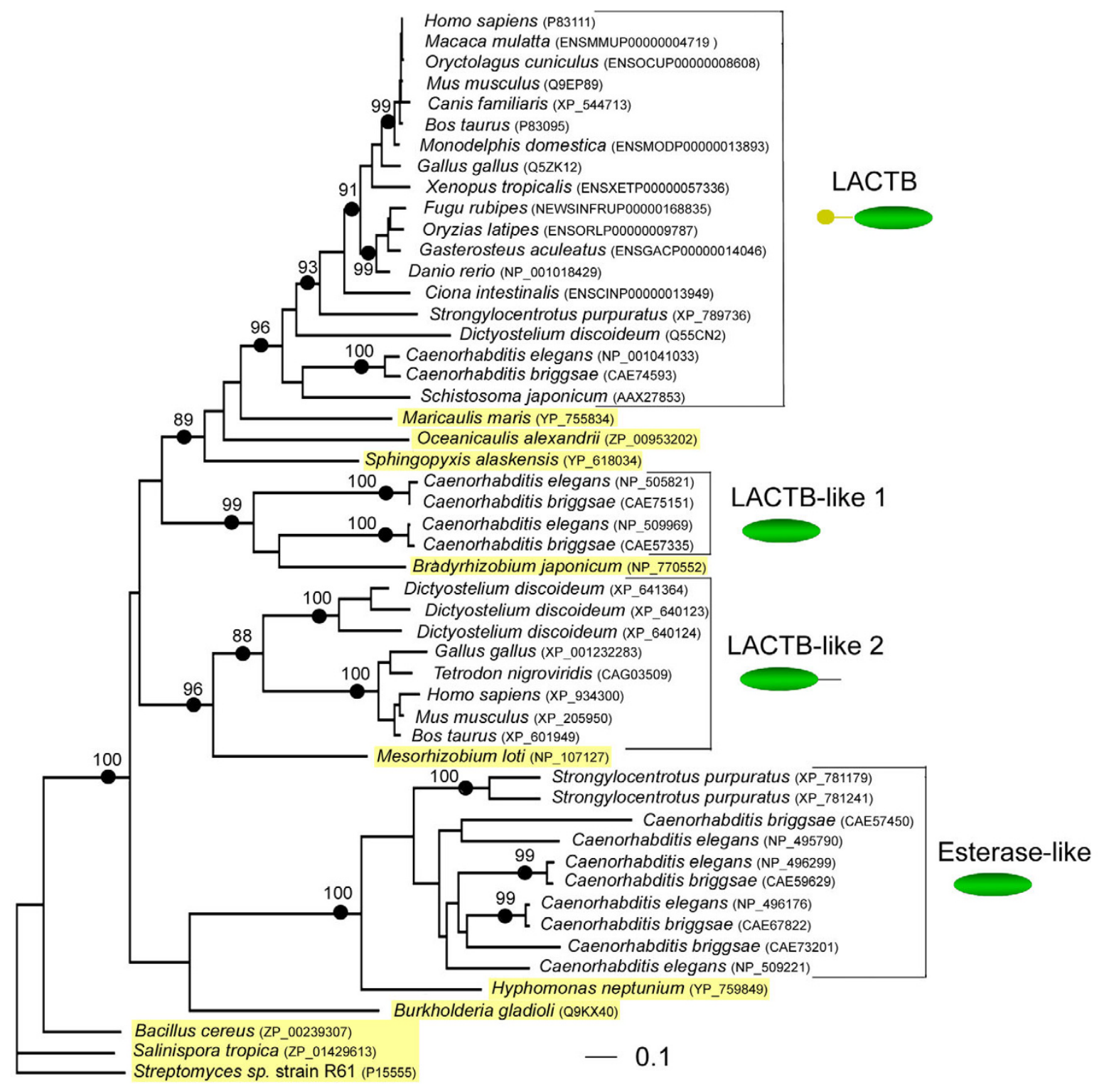

PBP- $\beta \mathrm{L} \quad$ mitochondrial tag

\section{Figure 3}

Inferred phylogenetic tree of the PBP- $\beta$ L domain of LACTB family proteins. An alignment encompassing 266 amino acids was analyzed by maximum likelihood as described in the Materials and Methods section. The log likelihood was -20487.28 and the $\Gamma$ distribution shape parameter shape parameter used was 2.670. Bootstrap values for nodes supported by more than 85 replicates of 100 are shown. Bacterial proteins are highlighted in yellow.

group common to all LACTB groups, suggests that the LACTB family is composed of four distinct alloparalogus protein lineages.

\section{The LACTB family derives from $\alpha$-proteobacterial ancestor proteins}

LACTB orthologs clustered together with LPBP-B proteins from the free-living $\alpha$-proteobacteria Maricaulis maris,
Oceanicaulis alexandrii, and Sphingopyxis alaskensis. This finding suggests that the progenitor of the LACTB orthologs was acquired from an early $\alpha$-proteobacterium. Interestingly, the evolutionary scenario appears to be similar for the other LACTB groups. Esterase-like proteins cluster with a putative esterase from Hyphomonas neptunium, the LACTB-like group 1 and 2 proteins cluster with putative peptidases from Bradyrhizobium japonicum and 
Mesorhizobium loti, respectively. These findings suggest that the progenitors for the LACTB family were acquired simultaneously from an early $\alpha$-proteobacterium harboring a set of four LPBP-B genes encoding structurally closely related proteins with different biochemical functions. That the LACTB groups cluster with proteins from different $\alpha$-proteobacterial lineages, may be explained by lineage-specific loss of LPBP-B genes resulting from the extensive genome reductions that has occurred throughout the evolution of $\alpha$-proteobacteria [27].

While LACTB orthologs have a relatively broad taxon distribution, proteins from the other three lineages are restricted to fewer taxa suggesting that widespread loss of these genes have occurred throughout the eukaryotic evolution. LACTB-like proteins 1 are found only in nematodes suggesting gene loss in all other lineages. In contrast, LACTB-like proteins 2 are abundant in Dictyostelium and comprise several vertebrate proteins, but do not occur in nematodes. The esterase-like proteins comprise five paralogs in nematodes and two in echinoderms, but appears to be missing from all vertebrates sequenced to date.

\section{Conclusion}

The PBP- $\beta$ L family encompasses a large number of highly diversified proteins in bacteria and eukaryotes. While the role of bacterial PBP- $\beta$ L proteins in peptidoglycan synthesis has been extensively studied, little is known about the function of metazoan PBP- $\beta \mathrm{L}$ family proteins. However, recent findings show that the mammalian mitochondrial PBP- $\beta$ L homolog LACTB is involved in metabolic signaling $[16,17,19]$. Therefore, clarifying the function of metazoan PBP- $\beta$ L homologs may reveal novel aspects about the evolution of metazoan energy metabolism and elucidate unknown mechanisms of metabolic regulation.

Our phylogenetic analysis indicated that the LACTB family is divided into four lineages deriving from four separate bacterial LPBP-B subclass genes. These genes were most likely acquired simultaneously from $\alpha$-proteobacteria by endosymbiotic gene transfer, although other scenarios such as multiple horizontal gene transfers from $\alpha$ proteobacteria to early organisms of the opistokont lineage can not be completely ruled out. The evolutionary history of the LACTB family is dominated by gene losses resulting in an uneven distribution of LACTB family proteins in metazoan taxa and no extant organism sequenced to date harbor proteins from all four lineages. Extensive diversification of LACTB family proteins appear to have occurred only in Nematodes. Since metazoan organisms lack peptidoglycan the widespread gene loss characterizing the history of the LACTB family may be readily explained by lack of enzymatic substrates. However, this raises the question as to what mechanisms have promoted the conservation of PBP- $\beta \mathrm{L}$ homologs in some eukaryotic lineages.

We speculate that phagocytotic feeding was the primary selection force acting to conserve genes for LPBP-B proteins in early eukaryotes. An early eukaryote organism possessing molecular machineries for both phagocytosis and effective peptidoglycan digestion would harness great benefit in an environment with numerous bacteria. It is thus possible that this hypothetical early eukaryote was endowed not only with the progenitors of the LACTB family proteins but was equipped with a larger complement of PBP- $\beta \mathrm{L}$ proteins and other peptidoglycan-degrading enzymes allowing an efficient and complete hydrolysis of ingested peptidoglycan. Following the diversification of eukaryotes, lineages in which phagocytotic feeding was deselected had no need for peptidoglycan-degrading enzymes and they were consequently lost from the genomes. On the contrary, eukaryote lineages leading to Dictyostelium and Caenorhabditis, which feed on bacteria, retained the genes for peptidoglycan-digesting enzymes and allowed them to undergo multiple duplications. This scenario implies that LACTB family proteins may also occur in some phagotropic protozoans.

LACTB orthologs are conserved in many metazoan species including all vertebrates currently sequenced. The energy metabolism of vertebrates is intimately linked to the metabolism of the large number of microbes that colonize the intestinal channel. That changes in the relative abundance of intestinal microbes from different taxa directly affects the lipid and carbohydrate metabolism of the host ([28] and references therein) demonstrates the existence of complex gut-microbe-to-host signaling mechanisms relayed by specific microbial metabolites. We hypothesize that LACTB is involved in the metabolism and/or sensing of some product(s) deriving from commensal bacteria. Further metagenomic, cell biological, and biochemical studies will be required to elucidate the function of PBP$\beta \mathrm{L}$ homologs in metazoan organisms.

\section{Methods}

Genomic DNA, expressed sequence tags, and protein databases were searched for nucleotide and amino acid sequences using BLAST 15/10/2006-15/01/2007. The following websites were used; Dictybase [29], DOE Joint Genome Institute [30], J. Craig Venter Institute [31], Hinvitational database [32], Human Genome Sequencing Center [33], LumbriBASE [34], National Center for Biotechology Information [35], Washington University School of Medicine Genome Sequencing Center [36], Wellcome Trust Sanger Institute [37], and Wormbase [38].

Orthologs to human LACTB were identified using a modified reciprocal best-hit approach as described $[20,21]$. To 
identify bacterial orthologs each LACTB family protein was used to search the NCBI nr database. Retrieved bacterial proteins were evaluated with the reciprocal best-hit test. Expectancy values (E-value) refer to searches in the NCBI nr sequence database. Binary alignments were made using Dotlet 1.5 [39] and LALIGN [40]. Multiple alignments of amino acid sequences were made using ClustalW and adjusted manually. Amino acid alignments are available upon request.

Phylogenetic maximum likelihood analysis of amino acid alignments was performed in software programs RAxMLVI [41] and proml from the PHYLIP package version 3.66 [42]. The invariant sites were removed from the alignment and the shape parameter of the $\Gamma$ distribution was estimated using ProtTest [43]. Four $\Gamma$ distribution classes with the JTT model were used in both programs. Trees were initially inferred in RAxML using the normal hill-climbing search with 100 random addition sequences. The resulting trees were further evaluated in proml, and the one giving the highest likelihood value is presented. The robustness of inferred trees was assessed by nonparametric bootstrapping using programs seqboot, proml, and consense from the PHYLIP package. One hundred replicates was used in the bootstrapping analysis. Like the majority of eukaryotic operational genes with bacterial homologs the LACTB family branched with homologs from Gram negative bacteria while homologs from Gram positive bacteria formed an outgroup. Therefore the Streptomyces $s p$. D-alanyl-D-alanine carboxypeptidase [SwissProt:P15555] was used to root the inferred tree.

The probability of mitochondrial import was estimated using Mitoprot mitochondrial targeting sequence prediction $[44,45]$. The Prosite [46] nomenclature for amino acid patterns was used.

\section{Abbreviations}

LPBP-B, low molecular weight penicillin-binding protein class $\mathrm{B}$; PBP- $\beta \mathrm{L}$, penicillin-binding protein and $\beta$-lactamase.

\section{Authors' contributions}

NP and ZP contributed equally to this study. All authors read and approved the manuscript.

\section{Additional material}

\section{Additional file 1}

Accession Numbers and Classification of a Set of Founding Members of the PBP- $\beta \mathrm{L}$ classes. Contains a list of founding members of the different $P B P-\beta L$ classes including additional references.

Click here for file

[http://www.biomedcentral.com/content/supplementary/14712148-8-26-S1.doc]

\section{Additional file 2}

Conserved Structural Elements in LPBP-Bs and LACTB. Contains a list of amino acids in conserved motifs found in LPBP-B proteins and LACTB. Click here for file

[http://www.biomedcentral.com/content/supplementary/14712148-8-26-S2.doc]

\section{Additional file 3}

Conserved PBP- $\beta$ L signature motifs in LACTB family proteins. Multiple amino acid alignment of $P B P-\beta L$ signature motif-containing segments from LACTB family proteins.

Click here for file

[http://www.biomedcentral.com/content/supplementary/14712148-8-26-S3.tiff]

\section{Acknowledgements}

This study was supported by grants from the Academy of Finland, the Sigrid Juselius Foundation, the Finska Läkaresällskapet, the Magnus Ehrnrooth foundation, the P. Albin Johansson foundation, and the Svenska Kulturfonden.

\section{References}

I. Macheboeuf P, Contreras-Martel C, Job V, Dideberg O, Dessen A: Penicillin Binding Proteins: key players in bacterial cell cycle and drug resistance processes. FEMS Microbiol Rev 2006, 30:673-691.

2. Goffin C, Ghuysen J-M: Biochemistry and Comparative genomics of SxxK Superfamily Acyltransferases Offer a Clue to the Mycobacterial Paradox: Presence of Penicillin-Susceptible Target Proteins versus Lack of Efficiency of Penicillin as Therapeutic Agent. Microbiol Mol Biol Rev 2002, 66:702-738.

3. Massova I, Mobashery S: Kinship and Diversification of Bacterial Penicillin-Binding Protein and $\beta$-Lactamases. Antimicrob Agents Chemother 1998, 42:1-17.

4. Ghuysen J-M: Penicillin-binding proteins. Wall peptidoglycan assembly and resistance to penicillin: facts, doubts and hopes. Int J Antimicrob Agents 1997, 8:45-60.

5. Bush K, Jacoby GA, Medeiros AA: A Functional Classification Scheme for $\beta$-Lactamases and Its correlation with Molecular Structure. Antimicrob Agents Chemother 1995, 39:12 II-1233.

6. Massova I, Mobashery S: Structural and Mechanistic Aspects of Evolution of $\beta$-Lactamases and Penicillin-Binding Proteins. Current Pharmaceutical Design 1999, 5:929-937.

7. Meroueh SO, Minasov G, Lee W, Shoichet BK, Mobashery S: Structural Aspects for Evolution of $\beta$-Lactamases from PenicillinBinding Proteins. J Am Chem Soc 2003, I 25:96|2-96/8.

8. Hall BG, Barlow M: Structure-Based Phylogenies of the Serine $\beta$-Lactamases. J Mol Evol 2003, 57:255-260.

9. Smith TS, Southan C, Ellington K, Campbell D, Tew DG, Debouck D: Identification, Genomic Organization and mRNA Expression of LACTB, Encoding a Serine $\beta$-Lactamase-like Protein with an Amino-terminal Transmembrane Domain. Genomics 200I, 78: 12-I4

10. Matagne A, Dubus A, Galleni M, Frère J-M: The $\beta$-lactamase cycle: a tale of selective pressure and bacterial ingenuity. Nat Prod Rep 1999, 16:1-19.

II. Liobikas J, Polianskyte Z, Speer O, Thompson J, Alakoskela J-M, Peitsaro $N$, Franck M, Whitehead MA, Kinnunen PJK, Eriksson O: Expression and purification of the mitochondrial serine protease LACTB as an $\mathbf{N}$-terminal GST fusion protein in Escherichia coli. Prot Pur Expr 2006, 45:335-342.

12. Koc EC, Burkhart W, Blackburn K, Moyer MB, Schlatzer DM, Mosely A, Spremulli MM: The Large Subunit of the Mammalian Mitochondrial Ribosome Analysis of the complement of ribosomal proteins present. J Biol Chem 200I, 267:43958-43969.

13. Moota VK, Brunkenborg J, Olsen JV, Hjerrild M, Wisniewski JR, Stahl E, Bolouri MS, Ray HN, Sihag S, Kamal M, Patterson N, Lander ES, 
Mann M: Integrated Analysis of Protein Composition, Tissue Diversity, and Gene Regulation in Mouse Mitochondria. Cell 2003, II I: 629-640.

14. Taylor SW, Fahy E, Zhang B, Glenn GM, Warnock DE, Wiley S, Murphy AN, Gaucher SP, Capaldi RA, Gibson BW, Ghosh SS: Characterization of the human heart mitochondrial proteome. Nature Biotech 2003, 21:28I-286.

15. Forner F, Arriaga EA, Mann M: Mild Protease Treatment as a Small-Scale Biochemical Method for Mitochondria Purification and Proteomic Mapping of Cytoplasm-Exposed Mitochondrial Proteins. J Proteom Res 2006, 5:3277-3287.

16. Rome S, Clément K, Rabsa-Lhoret R, Loizon E, Poitou C, Barsh GS, Riou J-P, Laville M, Vidal H: Microarray Profiling of Human Skeletal Muscle Reveals That Insulin Regulates $\sim 800$ Genes during a Hyperinsulinemic Clamp. I Biol Chem 2003, 278: $18063-18068$

17. Kim SC, Sprung R, Chen Y, Xu Y, Ball H, Pei J, Cheng T, Kho Y, Xiao H, Grishin NV, White M, Yang X-J, Zhao Y: Substrate and Functional Diversity of Lysine Acetylataion Revealed by a Proteomics Survey. Mol Cell 2006, 23:607-6I8.

18. Schwer B, Brunkenborg J, Verdin RO, Anderson JS, Verdin E: Reversible lysine acetylation controls the activity of the mitochondrial enzyme acetyl-CoA synthetase. Proc Natl Acad Sci USA 2006, 103: I0224-10229.

19. Lee J, Xy Y, Chen Y, Sprung R, Kim SC, Xe S, Zhao Y: Mitochondrial Phosphoproteome Revealed by an Improved IMAC Method and MS/MS/MS. Mol Cell Proteom 2007, 6:669-676.

20. Mushegian AR, Koonin EV: A minimal gene set for cellular life derived by comparison of complete bacterial genomes. Proc Natl Acad Sci USA 1996, 93:10268-10273.

21. Wall DP, Fraser HB, Hirsh AE: Detecting putative orthologs. Bioinformatics 2003, 19:1710-171I.

22. Kelly JA, Knox JR, Zhao H, Frère J-M, Ghuysen J-M: Crystalligraphic Mapping of $\beta$-Lactams Bound to a D-alanyl-D-alanyl peptidase target enzyme. J Mol Biol 1989, 209:28I-295.

23. Kelly JA, Kuzin AP: The Refined Crystallographic Structure of a DD-Peptidase Penicillin-target Enzyme at 16 A Resolution. J Mol Biol 1995, 254:223-236.

24. Rogozin IB, Wolf YI, Sorokin AW, Mirkin BG, Koonin EV: Remarkable Interkingdom Conservation of Intron Positions and Massive, Lineage-Specific Intron Loss and Gain in Eukaryotic Evolution. Curr Biol 2003, I3:15/2-1517.

25. Bompard-Gilles C, Remaut H, Villert V, Prangé T, Fanuel L, Delmarcelle M, Frère J, Van Beeumen J: Crystal structure of a D-aminopeptidase from Ochrobactrum anthropi, a new member of the 'penicillin-recognizing enzyme' family. Structure 2000 8(9):917-980.

26. Wagner UG, Petersen El, Schwab H, Kratky C: EstB from Burkholderia gladioli: $A$ novel esterase with a $\beta$-lactamase fold reveals steric factors to discriminate between esterolytic and $\beta$-lactam cleaving activity. Prot Sci 2002, I I:467-478.

27. Bossau B, Karlberg EO, Frank C, Legault B-A, Andersson SGE: Computational inference of scenarios for a-proteobacterial genome evolution. Proc Natl Acad Sci USA 2004, 26:9722-9727.

28. Turnbaugh PJ, Ley RL, Mahowald MA, Magrini V, Mardis ER, Gordon Il: An obesity-associated gut microbiome with increased capacity for energy harvest. Nature 2006, 444: I027-103I.

29. Dictybase [http://dictybase.org]

30. DOE Joint Genome Institute [http://www.jgi.doe.gov]

31. J. Craig Venter Institute [http://www.tigr.org]

32. H-invitational database [http://h-invitational.jp]

33. Human Genome Sequencing Center [http:// www.hgsc.bcm.tmc.edu]

34. LumbriBASE [http://www.earthworms.org]

35. National Center for Biotechology Information [http:// www.ncbi.nlm.nih.gov]

36. Washington University School of Medicine Genome Sequencing Center [http://www.genome.wustl.edu/
[ genome group index.cgi]

37. Wellcome Trust Sanger Institute [http://www.sanger.ac.uk]

38. Wormbase [http://www.wormbase.org]

39. Dotlet I.5 [http://myhits.isb-sib.ch/cgi-bin/dotlet]

40. [http://www.ch.embnet.org/software/LALIGN form.html].

41. Stamatakis A, Ludwig T, Meier H: RAxML III: A Fast Program for Maximum Likelihood-based Inference of Large Phylogenetic Trees. Bioinformatics 2005, 21:456-463.
42. Felsenstein J: Phylip, Phylogenetic Inference Package Distributed by the author. Department of Genetics, University of Washington, Seattle; 1993.

43. Abascal F, Zardoya R, Posada D: ProtTest: Selection of the bestfit models of protein evolution. Bioinformatics 2005, 21:2104-2105.

44. Claros MG, Vincens P: Computational method to predict mitochondrially imported proteins and their targeting sequences. Eur J Biochem 1996, 24 I:770-786.

45. Mitoprot [http://ihg.gsf.de/ihg/mitoprot.html]

46. Prosite [http://au.expasy.org/prosite]

47. Lindblad-Toh K, Wade CM, Mikkelsen TS, Karlsson E, Jaffe DB, Kamal M, Clamp M, Chang JL, Kulbokas III EJ, Zody MC, Mauceli E, Xie X, Breen M, Wayne RK, Ostrander EA, Ponting CP, Galibert F, Smith DR, deJong PJ, Kirkness E, Alvarez P, Biagi T, Brockman W, Butler J, Chin C-W, Cook A, Cuff J, Daly MJ, DeCaprio D, Gnerre S, Grabherr M, Kellis M, Kleber M, Bardeleben C, Goodstadt L, Heger A, Hitte C, Kim L, Koepfli K-P, Parker HG, Pollinger JP, Searle SM, Sutter NB, Thomas R, Webber C, Broad Institute Genome Sequencing Platform, Lander ES: Genome sequence, comparative analysis and haplotype structure of the domestic dog. Nature 2005, 438:803-8I9.

48. Caldwell RB, Kierzek AM, Arakawa $H$, Bezzubov $Y$, Zaim J, Fiedler $P$, Kutter S, Blagodatski A, Kostivska D, Koter M, Plachy J, Carnici P, Hayashizaki Y, Buerstedde J-M: Full-length cDNAs from chicken bursal lymphocytes to facilitate gene function analysis. Genome Biol 2004, 6:R6

49. Jaillon $\mathrm{O}$, Aury J-M, Brinet F, Petit J-L, Stange-Thomann N, Mauceli E, Bouneau L, Fischer C, Ozoef-Costaz C, Bernot A, Nicaud S, Jaffe D, Fisher S, Lutfalla G, Dossat C, Segurens B, Dasilva C, Salanoubat M, Levy M, Boudet N, Castellano S, Anthouard V, Jubin C, Castelli V, Katinka M, Vacherie B, Biémont C, Skalli Z, Cattolico L, Poulain J, de Berardinis V, Cruaud C, Duprat S, Brottier P, Coutanceau J-P, Gouzy J. Parra G, Lardier G, Chapple C, McKernan KJ, McEwan P, Bosak S, Kellis M, Volff J-N, Guigó R, Zody MC, Mesirov J, Lindblad-Toh K, Birren B, Nusbaum C, Kahn D, Robinson-Rechavi M, Laudet V, Schachter V, Quétier F, Saurin W, Scarpelli C, Wincker P, Lander ES, Weissenbach J, Crollius HR: Genome duplication in the teleost fish Tetraodon nigroviridis reveals the early vertebrate protokaryotype. Nature 2004, 431:946-957.

50. Dehal P, Satou Y, Campbell RK, Chapman J, Degnan B, De Tomaso A, Davidsom B, Di Gregorio A, Gelpke M, Goodstein DM, Harafuji N, Hastings KEM, Ho I, Hotta K, Huang W, Kawashima T, Lemaire P, Martinez D, Meinertzhagen IA, Necula S, Nonaka M, Putnam N, Rash S, Saiga H, Satake M, Terry A, Yamada L, Wang H-G, Awazu S, Azumi K, Boore J, Branno M, Chin-bow S, DeSantis R, Doyle S, Francino P, Keys DN, Haga S, Hayashi H, Hino K, Imai KS, Inaba K, Kano S, Kobayashi K, Kobayashi M, Lee B-I, Makabe KW, Manohar C, Matassi G, Medina M, Mochizuki Y, Mount S, Morishita T, Miura S, Nakayama A, Nishizaka S, Nomoto H, Ohta F, Oishi K, Rigoutsos I, Sano M, Sasaki A, Sasakura Y, Shoguchi E, Shin-i T, Spagnuolo A, Stainier D, Suzuki MM, Tassy O, Takatori N, Tokuoka M, Yagi K, Yoshizaki F, Wada S, Zhang C, Hyatt PD, Larimer F, Detter C, Doggett N, Glavina T, Hawkins T, Richardson P, Lucas S, Kohara Y, Levine M, Satoh N, Rokhsar DS: The Draft Genome of Ciona intestinalis: insights into Chordate and Vertebrate Origins. Science 2002, 298:2157-2167.

51. Stein LD, Bao Z, Blasiar D, Blumenthal T, Brent MR, Chen N, Chinwalla A, Clarke L, Clee C, Coghlan A, Coulson A, D'Eustachio P, Fitch DHA, Fulton LA, Fulton RE, Griffiths-Jones S, Harris TW, Hillier LW, Kamath R, Kuwabara PE, Mardis ER, Marra MA, Miner TL, Minx P, Mullikin JC, Plumb RW, Rogers J, Schein JE, Sohrmann M, Spieth J, Stajich JE, Wei C, Willey D, Wilson RK, Durbin R, Waterston RH: The Genome Sequence of Caenorhabditis briggsae: A platform for Comparative Genomics. PLoS Biol 2003, I:166-192.

52. [CSC] The C. elegans Sequencing Consortium: Genome Sequence of the Nematode $C$ elegans: A platform for Investing Biology. Science 1998, 282:2012-2018.

53. Eichinger L, Pachebat JA, Glöckner G, Rajandream M-A, Sucgang R, Berriman M, Song J, Olsen R, Szafranski K, Xu Q, Tunggal B, Kummerfeld S, Madera M, Konfortov BA, Rivero F, Bankier AT, Lehmann R, Hamlin N, Davies R, Gaudet P, Fey P, Pilcher K, Chen G, Saunders D, Sodergren E, Davis P, Kerhornou A, Nie X, Hall N, Anjard C, Hemphill L, Bason N, Farbrother P, Desany B, Just E, Morio T, Rost R, Churcher C, Cooper J, Haydock S, van Driessche N, Cronin A, Goodhead I, Muzny D, Mourier T, Pain A, Lu M, Harper D, Lindsay R, 
Hauser H, James K, Quiles M, Babu MM, Saito T, Buchrieser C, Wardroper A, Felder M, Thangavelu M, Johnson D, Knights A, Loulseged H, Mungall K, Oliver K, Price C, Quail MA, Urushihara H, Hernandez J, Rabbinowitsch E, Steffen D, Sanders M, Ma J, Kohara Y, Sharp S, Simmonds M, Spiegler S, Tivey A, Sugano S, White B, Walker D, Woodward J, Winckler T, Tanaka Y, Shaulsky G, Schleicher M, Weinstock G, Rosenthal A, Cox EC, Chisholm RL, Gibbs R, Loomis WF, Platzer M, Williams RRKJ, Dear PH, Noegel AA, Barrell B, Kuspa A: The genome of the social amoeba Dictyostelium discoideum. Nature 2005, 435:43-57.

Publish with Biomed Central and every scientist can read your work free of charge

"BioMed Central will be the most significant development for disseminating the results of biomedical research in our lifetime. " Sir Paul Nurse, Cancer Research UK

Your research papers will be:

- available free of charge to the entire biomedical community

- peer reviewed and published immediately upon acceptance

- cited in PubMed and archived on PubMed Central

- yours - you keep the copyright

Submit your manuscript here:

http://www.biomedcentral.com/info/publishing_adv.asp
BioMedcentral 